\title{
Evaluating urban neighbourhoods in terms of mobility performances, using open data and GPS tracks to assess actual people travel behaviour
}

\author{
Matilde Oliveti ${ }^{1}$, STEFAN Van Der SPEK ${ }^{1}$ \\ ${ }^{1}$ TUDelft University
}

Abstract

Managing urban areas has become one of the most important development challenges of the 21st century. Building sustainable cities is a major factor nowadays. In this context, the advent of technologies such as GPS (Global Positioning System) and GIS (Geographical Information Systems) enables to better address the relationship between urban form and people travel behaviour. Spatial and temporal data can be collected at once, giving an insight into the actual movement pattern of people. In this paper we make a contribution to the existing literature in mobility and urban studies by comparing a series of GIS-based neighbourhood indicators with the actual people travel behaviour detected by GPS survey. Information about built environment characteristics is retrieved by OpenStreetMap and other datasets. 10 different neighbourhoods in The Netherlands are compared and in the end the main features that characterize efficient neighbourhoods in terms of sustainable mobility patterns are identified.

Received on 14 November 2016; accepted on 07 September 2017; published on 20 December 2017

Keywords: GPS tracking, Open Data, OpenStreetMap, People Travel Behaviour, Mobility Patterns, Neighbourhoods Copyright @ 2017 Matilde Olivetil and STEFAN Van Der SPEK, licensed to EAI. This is an open access article distributed under the terms of the Creative Commons Attribution license (http://creativecommons.org/licenses/by/3.0/), which permits unlimited use, distribution and reproduction in any medium so long as the original work is properly cited.

doi:10.4108/eai.20-12-2017.153495

\section{INTRODUCTION}

With predictions that $66 \%$ of the world's population will live in urban areas by 2050 , Internet of Things technology is increasingly drawing the attention of city planners, engineers and architects [1]. Sustainability is a common thread in conversations about the Internet of Things and urban areas, as a truly smart city, complete with data from its citizens' behaviours, could drastically reduce pollution and waste.

Present urban development policy aims to achieve sustainable mobility patterns, shifting mobility to soft transportation modes such as walking and cycling [2]. In the past few decades travel patterns have become more complex, and policy makers demand more detailed information. As a result, conventional data collection methods seem no longer adequate to satisfy all data needs [3]. Recent advancements in positioning technologies, such as GPS (Global Positioning Systems), has enabled inexpensive and straightforward acquisition of movement data with handheld positioning devices [4]. This paper aims to provide empirical research on the relation between urban form and travel patterns, taking advantage of new technologies and open data. We intend to contribute both to studies on people travel behaviour, trying to demonstrate that the use of GPS tracks is a useful instrument to study people travel habits, and on the other hand to studies on mobility patterns and urban neighbourhood design. The general scope of this research is comparing the performance of different neighbourhoods in terms of mobility patterns, where mobility patterns stands for "where do people actually go?", "which mode of transportation do they use?", "what are their main destinations?". This research focuses on urban neighbourhoods in the Netherlands. In particular, 10 different neighbourhoods are considered in three different cities: Amersfoort, Zeewolde, and Veenendaal.

\section{RELATED WORK}

A lot of different studies have been developed regarding people travel behaviour in the last decades.
Most of them are related to psychological and social science and try to combine travel personal diaries with socio-economic and demographic statistics $[5,6]$. Not so many researches about people travel behaviour use GPS tracks data, since most of them tend to use traditional methods, such as paper travel diaries, phone recall surveys. It has been shown that data collected using these methods deviate systematically from actual behaviour [3]. GPS devices are mainly used for orientation, navigation and communication, but in some cases they can also be used as "sensors" for tracking and for measuring activities of people. Compared to traditional surveys, GPS offers clear advantages including the ability to collect all movements, precise times, locations, and routes; the chance to collect multiple days of travel; and a little burden on respondents [7]. GPS adds an important temporal dimension to research in urban design, primarily focused on spatial patterns, providing a new layer of knowledge that gives insight in processes and actual movement of people [4]. In the past, efforts were attempted by governments in order to reduce car mobility. For instance, in the '90s the Dutch government introduced the Vinex policy with the hope to influence peoples' travel behaviour by creating urban landscapes that invite people to use alternative modes of transportation. However, the results of this policy have not been very successful, as today the new districts developed are still too much oriented towards auto mobility [8]. Recently, several researches have been carried out to study travel patterns of the inhabitants of a small number of neighbourhoods in order to investigate to what extent certain spatial features of neighbourhoods provide an explanation for mobility [3,9]. The present research is built on this literature.

\section{CASE STUDY}

This study focuses on urban neighbourhoods in the Netherlands. In particular, 10 different neighbourhoods are considered in three different cities: six in Amersfoort, two in Zeewolde, and two in Veenendaal (see Table 1). The reasons behind this choice are the 
consistency of the data and of the GPS survey, and the diversity of the three cities in size, urban form and mobility facilities.

Table 1 Overview of neighbourhoods' statistics of 2012 [10].

\begin{tabular}{|c|c|c|c|}
\hline City & Neighbourhood & $\begin{array}{c}\text { Construction } \\
\text { period }\end{array}$ & $\begin{array}{c}\text { Avg. } \\
\text { number } \\
\text { of cars per } \\
\text { households }\end{array}$ \\
\hline \multirow{6}{*}{ Amersfoort } & Vathorst & $1990 \mathrm{~s}-2000 \mathrm{~s}$ & 1,075 \\
\hline & Nieuwland & late $1990 \mathrm{~s}$ & 1,1 \\
\hline & Kattenbroek & early $1990 \mathrm{~s}$ & 1 \\
\hline & Schothorst & $1970 \mathrm{~s}-1980 \mathrm{~s}$ & 0,75 \\
\hline & $\begin{array}{l}\text { Amersfoort city } \\
\text { centre }\end{array}$ & $1400-1500$ & 0,6 \\
\hline & Leusderkwartier & $1940 \mathrm{~s}-1950 \mathrm{~s}$ & 0,9 \\
\hline \multirow[b]{2}{*}{ Zeewolde } & Horsterveld & $1995-2005$ & 2,3 \\
\hline & Zeewolde Zuid & $\begin{array}{l}\text { Late 1980s- } \\
1990 \mathrm{~s}\end{array}$ & 1,2 \\
\hline \multirow{2}{*}{ Veenendaal } & $\begin{array}{l}\text { Dragonder } \\
\text { Noord }\end{array}$ & $1970 \mathrm{~s}$ & 1,1 \\
\hline & $\begin{array}{l}\text { Dichtersbuurt } \\
\text { Schepenbuurt }\end{array}$ & $\begin{array}{c}\text { 1970s-early } \\
\text { 1990s }\end{array}$ & 1,15 \\
\hline
\end{tabular}

Amersfoort is the second largest city of the province of Utrecht in central Netherlands. The city is growing quickly but has a wellpreserved and protected medieval centre. It is one of the largest railway junctions in the country.

Zeewolde is a town in the Flevoland province in the central Netherlands with a population of approximately 20.000. It is a new planned town in the early ' 80 s and it has no railway station. The municipality of Zeewolde was founded in 1984 and therefore it is one of the youngest in the Netherlands.

Veenendaal is a city in central Netherlands, which is part of the province of Utrecht. The municipality has a population of approximately 63.000. In 1997 it was elected the greenest city of Europe and in 2004 of the Netherlands and it has been also the top BikeCity of the Netherlands in 2000.

\section{METHODOLOGY}

This research proposes a new methodology for analysing and comparing a series of neighbourhoods taking into account facilities and infrastructure networks, respect to the real movement patterns of inhabitants.

With the purpose of describing the characteristics of the built environment in each neighbourhood, 17 GIS-based indicators

Permission to make digital or hard copies of all or part of this work for personal or classroom use is granted without fee provided that copies are not made or distributed for profit or commercial advantage and that copies bear this notice and the full citation on the first page. To copy otherwise, or republish, to post on servers or to redistribute to lists, requires prior specific permission and/or a fee.

UrbIoT'16, May 24-25, 2016, Tokyo, Japan.

Copyright 2016 ACM 1-58113-000-0/00/0010 ...\$15.00. were selected and organized into three groups (proximity, density, and accessibility), based on the classification Gil and Read [11] made in their work.

Proximity indicators are mainly related to measures like the distance to the closest railway station, bus stop, supermarket, etc.; density indicators are measures of intensity, such as the land use mix, green area density, buildings density, etc.; while accessibility indicators represent the mean distance to activities and facilities, like the percentage of buildings within a railway station, etc.

\subsection{Datasets}

The GPS tracks used in this study were derived from a previous GPS survey conducted in 2012 [12, 13]. In total, over 800 households were tracked for a week in the three Dutch cities. The raw data consisted of about 40 million GPS points.

Over the GPS tracks, information about the infrastructure networks and neighbourhood characteristics was retried from OpenStreetMap (OSM) [14], a digital map database of the world built through crowdsourced Volunteered Geographic Information (VGI). OSM data is freely available, it has universal coverage and a rich feature set that covers all modes of transportation. OSM seemed the most appropriate choice for the Netherlands, as it offers high semantic accuracy and it can have a very good level of completeness. Finally, additional datasets were used in this study to acquire information about addresses and buildings (BAG), land use (BBG) [15], and population (CBS) [16].

\section{DATA PROCESSING AND ANALYSIS}

\subsection{GIS-based indicators}

In order to compute the GIS-based indicators to assess characteristics of the built environment in each neighbourhood, a preliminary step was performed: the construction of the infrastructure networks. This operation was performed using the database PostgreSQL [17], through which all the data about roads, cycleway, footway, etc. was extracted in OSM. In the end three separated networks were created (car, cycle and walk networks), according to the different types of roads considered in OSM. Later, all proximity, density and accessibility indicators were computed using different tools and plugins in PostgreSQL and QGIS. For instance, within proximity indicators, it was measured the shortest path from the centre of each neighbourhood to the closest railway station (see Figure 1).

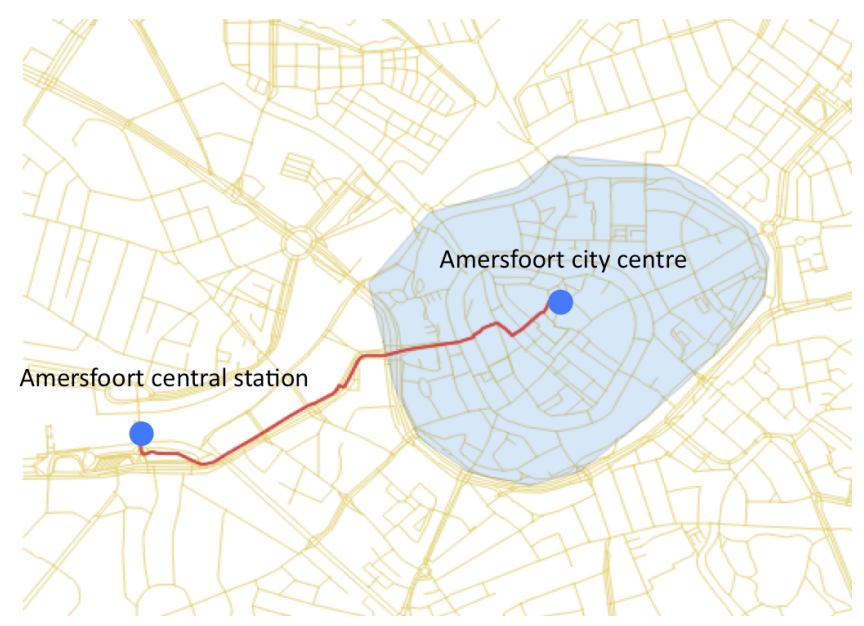

Figure 1 Shortest path between the city centre of Amersfoort and the central station with pedestrian network. 
Moreover, density indicators were used to measure land use mix in the different neighbourhoods, analysing the percentage of the diverse classes of land use (e.g. residential, reatil, industrial, etc.) (see Figure 2).

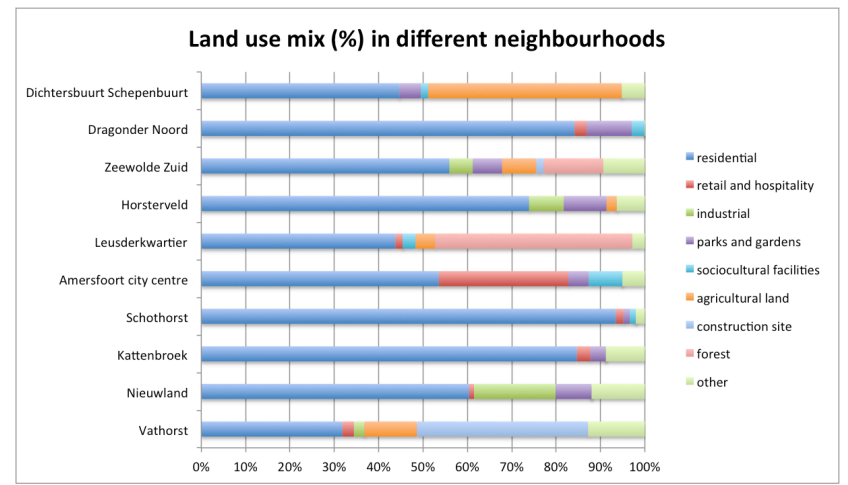

Figure 2 Overview of the land use mix in the different neighbourhoods.

\subsection{GPS tracks analysis}

After the GIS-based indicators implementation, the next step consisted in validating the built environment characteristics of each neighbourhood using GPS real data.

No effort was spent here in GPS data classification and trip segmentation, since it was out of the scope of this study. The GPS tracks used in this research were already pre-processed and classified in an interpretation-validation process made in previous studies [3]. A series of cleaning operations needed to be performed before analysing the GPS log. The amount of data was reduced, selecting only the GPS track points of the residents within the neighbourhoods.

The analysis of GPS tracks aimed to assess several aspects of actual people travel behaviour. First of all, travel modes were investigated counting GPS track points for each modality (car, bicycle, walk, etc.). Second, the most visited locations were taken into account, querying the GPS data in PostgreSQL in order to obtain the main destinations of households per neighbourhood. By filtering the track points based on the postal code and on the timestamp, only households' single visits were selected and analysed (see Figure 3).

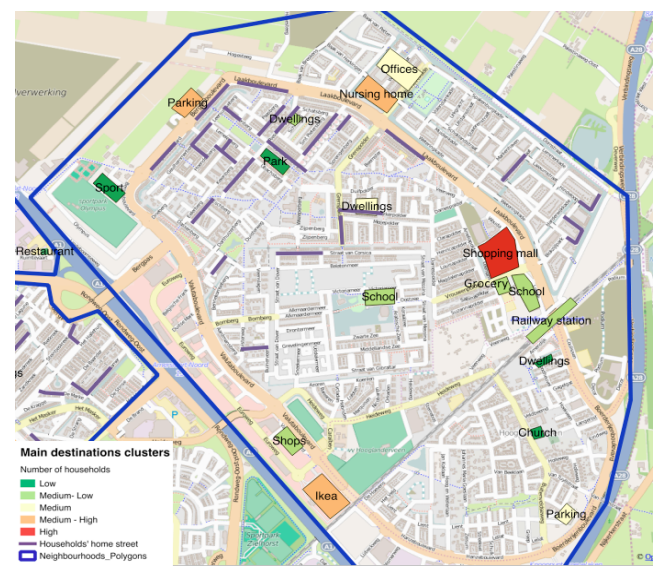

Figure 3 Main destinations in Vathorst, based on the number of visiting households.
Third, all the track points with travel mode classified as 'foot' were selected with the purpose to highlight where people actually walk. For each neighbourhood all the GPS walking track segments were then represented on a map (see Figure 4).

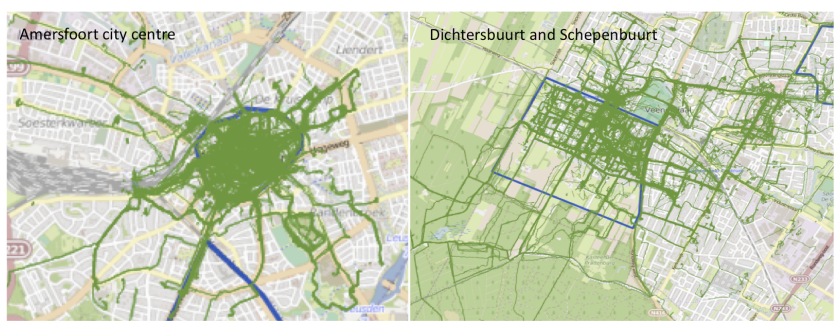

Figure 4 Walking travel mode trajectories in Amersfoort city centre and in Dichtersbuurt and Schepenbuurt.

\subsection{Statistical analysis}

A statistical analysis was carried out in order to be able to compare the results coming from the GIS-based indicator implementation and from the GPS analysis. First, the data was normalized using one of the most common normalization method in data mining: $z$-scores method. Then, the data was clustered and assembled in classes using the Natural Breaks method, chosen after having considered several clustering options.

Finally, a correlation test was run in order to see if a relationship existed between neighbourhood built environment characteristics and actual travel behaviour of inhabitants. Several correlation methods exist, but in this case Spearman correlation was used since there were only 10 cases and most of the variables were not normally distributed.

A score between 1 and 5 was assigned to each group of indicator (proximity, density and accessibility) with the aim to assess the overall performances of each neighbourhood. Each score represented a different level of performances: low, medium-low, medium, medium-high and high.

The spider diagram (see Figure 5) shows how each neighbourhood performs according to proximity, density and accessibility.
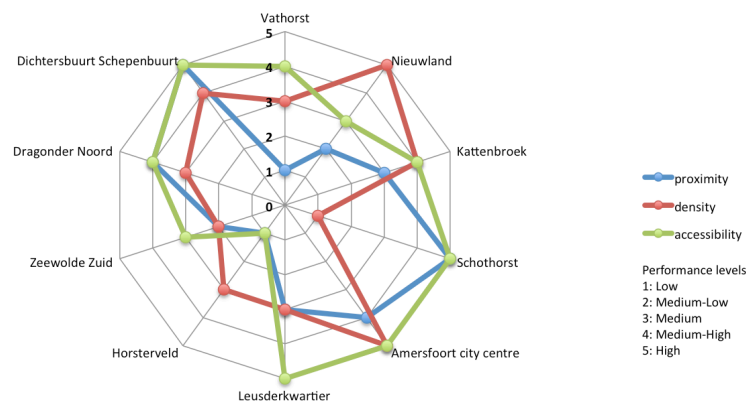

Figure 5 Neighbourhoods' performances in terms of proximity, density and accessibility. 


\section{DISCUSSION AND RESULTS}

After the analysis presented in the sections above, we came up to several conclusions and interesting results.

In general, the best neighbourhoods in terms of sustainable mobility were found to be Amersfoort city centre and Dichtersbuurt and Schepenbuurt. Amersfoort city centre ranked the best mainly because of:

- High population density.

- Wide building function types mix.

- High density of cycle and pedestrian network.

- Great accessibility of shops by walking and cycling within 5 minutes travel time.

Dichtersbuurt and Schepenbuurt ranked the best as well, but mainly because of:

- Proximity to railway station and bus stop.

- Great accessibility of railway station by driving, cycling and walking within 10 minutes travel time.

On the contrary, Horsterveld scored the worst, mainly due to:

- Remoteness of the railway station and of the motorway exit.

- Low buildings density.

- Bad accessibility of railway station within 10 minutes travel time.

- Bad accessibility of shops by walking within 5 minutes travel time.

- Low number of schools within $5 \mathrm{~km}$.

Analysing the overall results coming from the GPS analysis of the actual performances, it is clear that travel behaviour of households who live in Amersfoort city centre and Leusderkwartier is more sustainable in terms of mobility. In fact, residents in these two neighbourhoods tend to travel more by foot and by train and tend to use car less respect to residents of other neighbourhoods. In Vathorst and in the two neighbourhoods in Veenendaal there are still medium-high performances, mainly because of a frequent use of bike as travel mode. The lowest levels of actual mobility performances are recorded in Horsterveld and Zeewolde Zuid, where households are more willing to use the car instead of nonmotorized transportation means.

Thanks to the analysis of the case study, it is now possible to identify the general features that characterized an efficient neighbourhood in terms of sustainable mobility patterns:

- Closeness to the city centre, given the presence of various facilities and services, especially related to shopping.

- Diverse building function types, as they promote walking trips since services are better accessible.

- High building density, since people who live in highdensity neighbourhoods tend to walk more, because all the facilities are much closer to each other.

- High pedestrian and cycle network density, as a large presence of pedestrian streets and cycle paths can encourage the use of non-motorized transport modes.

- Great accessibility to railway station, since people are more willing to travel by train if the railway station is close by.
- Great accessibility of bus stops and good level of service, as it promotes the use of public transport.

\section{CONCLUSIONS}

In this paper we make a contribution to the existing body of knowledge in mobility studies by comparing a series of GIS-based neighbourhood indicators with the actual people travel behaviour detected by GPS survey. This study provides empirical research on the relation between urban form and travel patterns, taking advantage of new technologies and open data. Thank to the use of GPS real data, today it is possible to validate current statistics with actual data, adding a new layer of knowledge to mobility studies.

This research brings points of innovation to the existing literature in the field of mobility studies. In fact, thanks to the availability of new tools and thanks to the upgrade of computing power, nowadays many calculations have become much simpler and indicators from some time ago can now be enhanced.

The indicators are chosen in such a way that they can be easily understood and interpreted by researchers, planners and policy makers. In doing so, the indicators are more likely to be used in mobility evaluation studies and to have impact on the policy making process. In fact, the methodology presented can be used for investigating sustainable mobility potential of neighbourhoods during planning stages of new neighbourhoods, but also for monitoring performance, propose policy and planning interventions on existing neighbourhoods. Thanks to the use of datasets like OpenStreetMap, which is open and available worldwide, the same procedure can be applied in several cases.

The method of validating spatial indicators by GPS real data has demonstrated to be successful and to have a lot of potential for the future, especially if considering the wide availability of GPS Apps in devices like smartphones and tablets.

\section{FUTURE RESEARCH}

The work described in this paper can be improved in the future. Here we address some recommendations for future work. First, improving the implementation of the theoretical performance indicators could be a possibility. Improving for instance the computation of the shortest path and using additional datasets to add information to the network can lead to a more precise measure of distance.

Regarding the density indicators, improvements can be made especially for the analysis of land use mix and the building function types.

The list of the theoretical performance indicators can always be changed and improved in future research. Some indicators may be found to have limited impact on the analysis, and therefore new indicators may be added to the list.

Furthermore, as indicators may have different influence on the final results, a series of weights may be applied in order to level them.

Finally, the accuracy of the study related to the main destinations can get better if using additional technologies, such as Wi-Fi, Bluetooth or RFID, which are often used in indoor environments. In fact, as we know, GPS reception is not so good indoors, since it really depends on the building material. In a concrete building, almost no GPS track point is logged. Therefore, a possibility 
would be to use GPS for tracking people outdoors, while using other technologies to track people indoors. In such a way, the accuracy of the actual performances could be enhanced.

\section{REFERENCES}

[1] United Nations, Department of Economic and Social Affairs, Population Division (2015). World Urbanization Prospects: The 2014 Revision, (ST/ESA/SER.A/366).

[2] Gil, J. 2010. Urban form and the multi-modal mobility network structure. Evaluating the sustainable accessibility of urban areas in the city-region. $\mathrm{PhD}$ review report, TU Delft

[3] Bohte, W., Maat, K., and Quak, W. (2008). A method for deriving trip destinations and modes for GPS-based travel surveys. In J. Van Schaick, \& S. Van der Spek (Eds.) Urbanism on Track, chap. 10, (pp. 129-145). IOS Press.

[4] Van der Spek, S., Van Schaick, J., De Bois, P., and De Haan, R. (2009). Sensing Human Activity: GPS Tracking. Sensor Journal, ISSN 1424-8220

[5] Beirão, G., and Cabral, J.S. (2005). Modeling Service Quality for Public Transport Contracts: Assessing Users Perceptions. http://hdl.handle.net/10216/67471, 9th Conference on Competition and Ownership in Land Transport

[6] Jensen, M. (1999). Passion and heart in transport - a sociological analysis on transport behaviour. Pergamon, Transport Policy 6 (1999) 19-33

[7] Wolf, J., Bachman, W., Oliveira, M.S. et al. (2014). Applying GPS Data to Understand Travel Behaviour. Volume I: Background, Methods, and Tests. National Cooperative Highway Research Program, report 775, Transportation Research Board, Washington, D.C.

[8] Snellen, D., and Hilbers, H. (2007). Mobility and Congestion Impacts of Dutch VINEX Policy. Tijdschrift Voor Economische En Sociale Geografie 98 (3): 398-406.
[9] Meurs, H., and Haaijer, R. (2001). Spatial structure and mobility. Transportation Research Part D $6429 \pm 446$, Elsevier

[10] Centraal Bureau voor de Statistiek (CBS) (2014). Kerncijfers wijken en buurten 2004-2012. http://www.cbs.nl/nl$\mathrm{NL} / \mathrm{menu} /$ themas/dossiers/nederlandregionaal/cijfers/incidenteel/maatwerk/wijkbuurtstatistieken/kwb-recent/default.htm

[11] Gil, J., and Read, S. (2012). Measuring sustainable accessibility potential using the mobility infrastructure's network configuration. PAPER REF \# 8104 Proceedings: Eighth International Space Syntax Symposium Santiago, PUC

[12] Bohte, W. (2010). Residential self-selection and travel. The relationship between travel-related attitudes, built environment characteristics and travel behaviour. In Sustainable Urban Areas, Delft University Press

[13] Onderzoek verplaatsingsgedrag, Research on travel behaviour, May 2105. URL:

http://www.verplaatsingsgedrag.nl/index5.html

[14] Openstreetmap. OpenStreetMap Wiki, January 2015. URL http://wiki.openstreetmap.org/wiki/Main Page

[15] Bodemgebruik Nederland. Land use Netherland BBG, February 2015 URL

http://www.compendiumvoordeleefomgeving.nl/indicatoren/ nl0061-Bodemgebruikskaart-voor-Nederland.html?i=15$\underline{18 C e n t r a a l ~ B u r e a u ~ v o o r ~ d e ~ S t a t i s t i e k ~(C B S), ~(2014) . ~}$ Onderzoek verplaatsingen in Nederland 2013 (OViN). http://www.cbs.nl/NR/rdonlyres/E29E2FB9-F7CF-4B0EB497-E09C8F1F6AA1/0/2014ovin2013.pdf

[16] PostgreSQL. Database Management Systems, January 2015, URL http://www.postgresql.org/

[17] QGIS. QuantumGIS, Geographical Information Systems, January 2015, URL https://www.qgis.org/en/site/forusers/download.html 